\title{
Cardiorespiratory fitness, muscular strength and risk of type 2 diabetes: a systematic review and meta-analysis
}

\author{
Jakob Tarp ${ }^{1,2}$ D $\cdot$ Andreas P. Støle ${ }^{3} \cdot$ Kim Blond $^{4} \cdot$ Anders Grøntved $^{1}$
}

Received: 3 January 2019 / Accepted: 7 March 2019 /Published online: 23 April 2019

(C) The Author(s) 2019

\begin{abstract}
Aims/hypothesis The study aimed to quantitatively summarise the dose-response relationships between cardiorespiratory fitness and muscular strength on the one hand and risk of type 2 diabetes on the other and estimate the hypothetical benefits associated with population-wide changes in the distribution of fitness.

Methods We performed a systematic review with meta-analysis. The PubMed and EMBASE electronic databases were searched from inception dates to 12 December 2018 for cohort studies examining the association of cardiorespiratory fitness or muscular strength with risk of incident type 2 diabetes in adults. The quality of included studies was evaluated using the Newcastle-Ottawa Scale.

Results Twenty-two studies of cardiorespiratory fitness and 13 studies of muscular strength were included in the systematic review with both exposures having ten estimates available for the primary adiposity- or body size-controlled meta-analysis. In random-effects meta-analysis including 40,286 incident cases of type 2 diabetes in 1,601,490 participants, each 1 metabolic equivalent (MET) higher cardiorespiratory fitness was associated with an 8\% (95\% CI 6\%, 10\%) lower RR of type 2 diabetes. The association was linear throughout the examined spectrum of cardiorespiratory fitness. In 39,233 cases and 1,713,468 participants each 1 SD higher muscular strength was associated with a 13\% (95\% CI 6\%, 19\%) lower RR of type 2 diabetes. We estimated that $4 \%$ to $21 \%$ of new annual cases of type 2 diabetes among $45-64$-year-olds could be prevented by feasible and plausible population cardiorespiratory fitness changes.

Conclusions/interpretation Relatively small increments in cardiorespiratory fitness and muscle strength were associated with clinically meaningful reductions in type 2 diabetes risk with indication of a linear dose-response relationship for cardiorespiratory fitness.
\end{abstract}

Registration: PROSPERO (CRD42017064526).

Keywords Epidemiology $\cdot$ Fitness $\cdot$ Meta-analysis $\cdot$ Physical activity $\cdot$ Public health $\cdot$ Systematic review $\cdot$ Type 2 diabetes

Electronic supplementary material The online version of this article (https://doi.org/10.1007/s00125-019-4867-4) contains peer-reviewed but unedited supplementary material, which is available to authorised users.

Jakob Tarp

jakob.tarp@nih.no

1 Research Unit for Exercise Epidemiology, Centre of Research in Childhood Health, Department of Sports Science and Clinical Biomechanics, University of Southern Denmark, Odense, Denmark

2 Department of Sports Medicine, Norwegian School of Sports Sciences, Sognsveien 220, 0806 Oslo, Norway

3 Department of Sports Science and Clinical Biomechanics, University of Southern Denmark, Odense, Denmark

4 Center for Clinical Research and Prevention, Bispebjerg and Frederiksberg Hospital, The Capital Region,

Frederiksberg, Denmark

\begin{tabular}{ll}
\multicolumn{2}{l}{ Abbreviations } \\
D+L & $\begin{array}{l}\text { DerSimonian and Laird } \\
\text { FRIEND }\end{array}$ \\
& $\begin{array}{l}\text { Fitness Registry and the Importance } \\
\text { of Exercise National Database }\end{array}$ \\
GLST & $\begin{array}{l}\text { Generalised least squares trend } \\
\text { I-V }\end{array}$ \\
Inverse variance \\
MET & Metabolic equivalent \\
NOS & Newcastle-Ottawa Scale \\
PIF & Potential impact fraction
\end{tabular}

\section{Introduction}

Type 2 diabetes prevention is a key health priority of the 21 st century $[1,2]$. Lifestyle interventions including engagement 


\section{Research in context}

\section{What is already known about this subject?}

- The risk of type 2 diabetes is lower in individuals with high levels of cardiorespiratory fitness or muscular strength

- The benefits of population-wide changes in fitness on total type 2 diabetes incidence are unknown

- There have been no previous attempts to synthesise evidence for muscular strength in a systematic review or metaanalysis

\section{What is the key question?}

- What are the shape and magnitude of the dose-response relationships between cardiorespiratory fitness and muscular strength on the one hand and risk of type 2 diabetes on the other, and how might population-wide changes in fitness impact on type 2 diabetes incidence?

\section{What are the new findings?}

- In the largest meta-analysis to date, a 1 metabolic equivalent (MET) higher cardiorespiratory fitness was associated with an $8 \%$ lower risk of type 2 diabetes with a linear dose-response relation

- A 1 SD higher muscular strength was associated with a $13 \%$ lower risk of type 2 diabetes but with much larger variation in effect sizes between studies than was observed for cardiorespiratory fitness

- The hypothetical impact of successful changes in the population distribution of cardiorespiratory fitness among 45-64-year-old US men and women varied from $4 \%$ to $21 \%$ of new annual cases of type 2 diabetes that could be prevented

\section{How might this impact on clinical practice in the foreseeable future?}

- Clinicians and public health authorities should encourage and promote physical activities challenging maximal aerobic capacity and/or maximal muscular strength as preventive strategies for type 2 diabetes

in physical activity are established primary $[3,4]$ and secondary preventive strategies [5]. These lifestyle interventions are supported by evidence from observational studies convincingly showing that engagement in higher levels of physical activity is associated with lower risk of subsequent type 2 diabetes [6, 7]. Physical activity influences both cardiorespiratory fitness [8], which reflects the capacity of the cardiovascular system, and muscular fitness [9], which is a construct encompassing muscular strength, power and endurance [10]. Cardiorespiratory and muscular fitness phenotypes can be accurately and precisely quantified $[10,11]$ using methods that are feasible in a clinical setting [12]. Determining the dose-response relationships of these objective markers with incidence of type 2 diabetes may help provide tangible targets for individual and population physical activity prescriptions and interventions.

Attempts to quantitatively summarise the association between cardiovascular fitness and risk of type 2 diabetes from prospective cohort studies $[6,13]$ have been limited by (1) assuming a linear dose-response association [13]; (2) pooling estimates with and without control for adiposity [13] despite substantial attenuation of fitness-diabetes associations when adiposity is controlled for [14-16]; and (3) not exploring other sources of heterogeneity $[6,13]$. A recent meta-analysis addressed these limitations [17] but did not translate their findings into absolute public health metrics. Such metrics are needed to guide allocation of public health resources.
Further, a landmark study including more than one million individuals [18] was not included in the meta-analysis. No previous systematic review or meta-analysis of the association between muscular fitness and type 2 diabetes incidence exists.

The purpose of this study was to (1) systematically review and meta-analyse prospective cohort studies reporting on the association of cardiovascular and muscular fitness with the risk of incident type 2 diabetes; (2) investigate sources of heterogeneity including the importance of adjustment for adiposity; and (3) inform public health policy by estimating relevant absolute risk metrics of the population-wide impact of fitness on type 2 diabetes risk.

\section{Methods}

The study protocol was registered with PROSPERO (CRD42017064526) and reported according to Metaanalysis Of Observational Studies in Epidemiology (MOOSE) guidelines. Ethics approval was not required.

Data sources and searches PubMed and EMBASE were searched for cohort studies on the associations among cardiorespiratory fitness, muscular strength and risk of incident type 2 diabetes (electronic supplementary material [ESM] Table 1 and ESM Table 2). No restrictions on date of publication were 
set. The final search was conducted on 12 December 2018 . We additionally went through reference lists from studies included in the review and searched Web of Science for studies citing these publications.

Study selection Cohort studies were eligible if they (1) followed individuals free of type 2 diabetes at baseline, but we included cohorts of individuals with diabetes-associated conditions (e.g. dyslipidaemia or obesity); (2) assessed cardiorespiratory fitness using a maximal or sub-maximal test of any form at baseline or assessed muscular strength using a test requiring a maximal effort at baseline; (3) considered incidence of type 2 diabetes as an isolated outcome; and (4) were published in Scandinavian or English language. Conference abstracts were included if relevant. Restriction to muscular fitness operationalised by maximal strength (thereby excluding muscular power and endurance) [10] was chosen to maximise the potential for exposure harmonisation. Studies were excluded if they (1) considered a cohort of individuals with a chronic disease (e.g. cancer); or (2) assessed muscular endurance or power (full details in ESM Table 3). To be included in meta-analysis, studies additionally had to provide (1) HR, OR or RR for type 2 diabetes for one or more cardiorespiratory fitness or muscular strength estimates (linear or categorical); (2) estimates of variance or data to calculate it; and (3) had cardiorespiratory fitness estimates convertible to metabolic equivalents (METs) [10] or muscular strength estimates convertible to per SD. Two researchers (J. Tarp and A. P. Støle) independently screened titles and abstracts using Endnote X7.7.1 (Clarivate Analytics, PA, USA) according to prespecified criteria. When eligibility was ambiguous, the full text was retrieved. Disagreement was resolved by discussion including a third researcher (A. Grøntved).

Data extraction and quality assessment Data from eligible studies were independently extracted by two researchers (J. Tarp and A. P. Støle) using a piloted template. Disagreements were resolved by discussion. The following were extracted if available: first author, country, cohort name/title, cohort recruitment period (years), sex, ethnicity, baseline age, length of follow-up, method of outcome ascertainment, cumulative diabetes incidence, method of exposure ascertainment, levels of exposure, case count and total participant count in fitness categories, HRs/ORs/RRs and associated variance for linear or categorical estimates, and control variables applied in retrieved estimates. From each study or cohort we extracted estimates with and without control for an index of adiposity if available. We extracted adiposity- and non-adipositycontrolled estimates from the same report if possible, but included other reports from the same cohort if this increased sample sizes or the number of cases or facilitated a more direct BMI contrast. When a study did not provide either (1) estimates with and without adiposity control; or (2) estimates from at least two categories compared with a common reference, we contacted corresponding authors and requested additional information using a standardised template (template available on request to the corresponding author). The Newcastle-Ottawa Scale (NOS) [19] with modifications informed by the study question was used to rate overall study quality (details of the NOS rating and criteria in ESM Table 4 and ESM Table 5). Age, sex, ethnicity, cardiorespiratory/ muscular fitness, smoking [20], family history of diabetes, dietary intake [21], alcohol consumption [22], TV viewing [23] and socioeconomic status were considered putative confounding variables which could potentially result in biased measures of association. When multiple publications from the same cohort were identified, we used the manuscript presenting the largest case and participant count with harmonisable exposure data (table of overlapping cohorts presented in ESM Table 6). If additional data (e.g. linear/ categorical or with/without control for adiposity) from the cohort were available in other publications, we retrieved estimates from both of these papers.

Data synthesis A detailed overview of assumptions, calculations and unpublished data provided by contacted authors used in exposure harmonisation is provided in ESM Table 7 and ESM Table 8. If possible, cardiorespiratory fitness estimates were converted to METs for the non-linear analysis and to per 1 MET increase for the linear meta-analysis. Muscular strength was converted to per SD increase. Harmonisation of linear estimates was performed using transformation of the log-ratio estimate (using the natural logarithm) [24] under the assumption of fitness measures following a normal distribution and a log-linear association with type 2 diabetes incidence. Estimates for cardiorespiratory fitness based on treadmill duration were converted using exercise protocolappropriate equations [25]. When the exposure level was unclear, but distributional assumptions allowed estimation, we assumed an SD of cardiorespiratory fitness of 2.0 METs [26, 27] in subsequent calculations. Cardiorespiratory fitness presented as watts per $\mathrm{kg}$ was converted to $\mathrm{ml} \mathrm{O}_{2} \mathrm{~kg}^{-1} \mathrm{~min}^{-1}$ using a linear equation based on measurement of maximal oxygen uptake by indirect calorimetry (variance explained was $71 \%$ [ESM Table 7]). Data provided as $\mathrm{ml} \mathrm{O}_{2}$ $\mathrm{kg}^{-1} \mathrm{~min}^{-1}$ were converted to METs by dividing by 3.5 [10]. When original estimates did not have the lowest fitness category as reference, we converted the lowest fitness level to the reference using the Hamling method [28].

Statistical analysis Harmonised estimates for cardiorespiratory and muscle strength were pooled using a random-effects model [29] under the assumption of a linear dose-response relationship and that each study provides an estimate in a distribution of 'true' estimates. We provide fixed-effects estimates for comparison. If studies provided HRs/RRs/ORs pertinent to 
a continuous form we used this estimate. Otherwise, and if at least two categories with a common reference were available, we used generalised least squares trend (GLST) estimation to estimate the study-specific dose-response association [30] taking into account the common reference group [31] and the non-zero exposure in the reference group by centring the exposure corresponding to the natural log RR [32]. In addition, we modelled the dose-response association between cardiorespiratory fitness and type 2 diabetes using restricted cubic splines with knots placed at the 25th, 50th and 75th percentiles [33] of the cardiorespiratory fitness distribution in the data. Departure from linearity was assessed by a Wald test examining the null hypothesis that the coefficient of the second spline was equal to zero [34]. At least two categories with a common reference were needed to be included in non-linear analysis. Insufficient data precluded non-linear analysis of muscular strength. Analyses were performed separately on estimates reported with and without inclusion of adiposity indices as control variables. Adiposity-adjusted estimates were included as primary analysis as we consider this the more conservative analysis. We present data for men and women separately if available but used a fixed-effects meta-analysis to pool estimates within a study based on other stratifications if relevant. ORs were assumed to approximate RRs [35]. Between-study heterogeneity was formally assessed using $I^{2}$ as a measure of the proportion of variance not explained by random error and by visual interpretation of the forest plots. Sources of heterogeneity were explored by stratification on cohort and participant characteristics. Robustness of estimates was assessed by repeating the analysis excluding a single study at a time. Risk of small-study bias was investigated by funnel plot and Egger's test for asymmetry. Estimates are presented with a 95\% CI. Assuming that estimates represent causal effects, we calculated the risk difference for a 1 MET and a $1 \mathrm{SD}$ increase in cardiorespiratory fitness and muscular strength, respectively. The risk differences (with 95\% CIs) were calculated using the formula: risk difference $=$ background incidence rate $\times(R R-1)$ [36]. We calculated risk differences based on background annual rates in the age strata 18-44, 45-65 and $\geq 65$ years based on 2015 US incidence data [37]. We calculated potential impact fractions (PIFs) $[38,39]$ as a measure of the percentage of new annual diabetes cases in the population that could hypothetically be prevented by interventions affecting the population distribution of cardiorespiratory fitness. Our hypothetical interventions were modelled on sex-specific population estimates of cardiorespiratory fitness for 40-59-year-olds from the US Fitness Registry and the Importance of Exercise National Database (FRIEND) [40]. PIFs were calculated under four counterfactual scenarios: (1) a structural intervention resulting in a 1 MET increase in the bottom $50 \%$ of the cardiorespiratory fitness distribution; (2) the same intervention but resulting in a population-wide 1 MET fitness increase; (3) achievement of the same cardiorespiratory fitness distribution as observed in age-matched individuals from the Norwegian populationbased HUNT study [41]; and (4) achievement of cardiorespiratory fitness distribution identical to the most physically active tertile of age-matched individuals from the HUNT study [41]. Additional details are given in ESM Table 9. We were unable to calculate PIFs for muscular strength as no reference distribution was identified. All $p$ values were two-sided and interpreted at the 0.05 level. Analyses were performed in Stata 15.0 (StataCorp, College Station, TX, USA).

\section{Results}

Literature search In total, 22 studies (representing 18 unique cohorts) on cardiorespiratory fitness [13, 14, 18, 42-60] and 13 studies on muscular strength $[15,16,18,43,61-69]$ were identified for inclusion in the systematic review. The phases of the literature search are shown in Fig. 1. Additional data were retrieved by personal communication to six cohorts for cardiorespiratory fitness $[18,45,48-50,52]$ and five for muscular strength [16, 18, 63, 65, 68].

Study characteristics Cohort studies reporting estimates for cardiorespiratory fitness ranged in size from 571 to $1,534,425$ participants with a median cohort baseline age of 45 years. The cumulative incidence of type 2 diabetes ranged from $0.7 \%$ to $26.2 \%$ with median follow-up ranging from 3 to 29 years. Nine cohorts used a maximal test while eight used a sub-maximal assessment of fitness. For muscular strength, cohort sizes ranged from 328 to $1,534,425$ participants. The median cohort age at baseline was 52 years. The cumulative incidence of type 2 diabetes ranged from $2.1 \%$ to $18.5 \%$ with median duration of follow-up ranging from 3 to 26 years. Eight studies reported muscle strength normalised to kilogram body weight (two of these after receiving additional data from study authors) while five did not normalise muscular strength. Eleven studies used maximal handgrip strength to define muscular strength while two used a composite index including multiple muscle groups. The median SD of muscular strength as a percentage of the mean was $31 \%$ (range: $22-39 \%$ ). Of the 31 studies considered, only four used a measure other than BMI to control for adiposity. The median NOS score was six for cardiorespiratory fitness and six for muscular strength. Importantly, all studies failed to account for at least four of the seven pre-specified confounding factors with potentially nontrivial impact on the internal validity of risk estimates. An overview of study characteristics is presented in ESM Table 10 and ESM Table 11. Seven studies for cardiorespiratory fitness [54-60] and two studies for muscular strength [67, 69] presented data that were not harmonisable for inclusion in meta-analysis. Results from these studies generally supported 
Fig. 1 Flowchart of retrieved publications

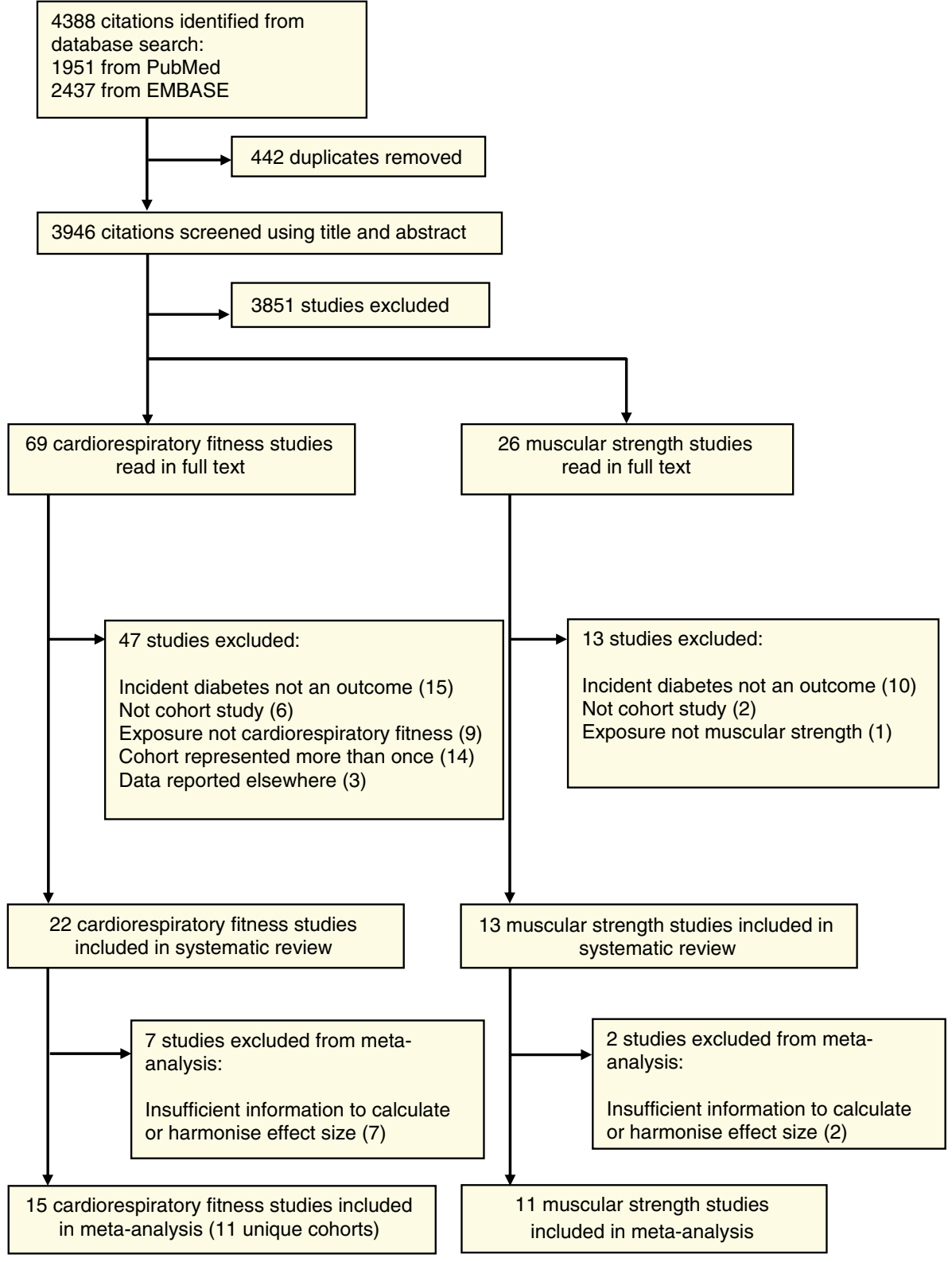

a protective effect of higher cardiorespiratory fitness and muscular strength on risk of type 2 diabetes.

\section{Association between cardiorespiratory fitness and risk of type} 2 diabetes In adiposity-controlled models including 40,286 incident cases of type 2 diabetes in 1,601,490 participants, each 1 MET higher cardiorespiratory fitness was associated with an $8 \%(95 \%$ CI $6 \%, 10 \%)$ reduction in risk of type 2 diabetes $[13,14,18,44,45,48-50,52,53]$. The per 1 MET risk reduction in models omitting adiposity control was $20 \%$ (95\% CI 14\%, 25\%) [14, 43-48, 50-52]. Study-specific per 1 MET estimates are shown as forests plots with (Fig. 2) and without (ESM Fig. 1) adiposity control.

The non-adiposity-controlled meta-analysis was highly sensitive to the choice of random- or fixed-effects modelling; estimated heterogeneity was substantial in both models $\left(I^{2}\right.$ $83 \%$ and $93 \%$, respectively), whereas visual inspection of the forest plots suggested moderate heterogeneity. Heterogeneity appeared to be explained by the influence of two studies, one with a noticeably narrow 95\% CI [18] and one with a substantial effect size and a moderate size CI [45]. Excluding these studies reduced the $I^{2}$ to $48 \%$. The association between adiposity-controlled cardiorespiratory fitness and type 2 diabetes risk modelled using restricted cubic splines [14, 18, 42, 44, 45, 48-50, 52, 53] is shown in Fig. 3. The model was consistent with a continued linear risk reduction with no statistical support of a non-linear association $(p=0.07)$ within our data ranging from four to 15 METs. A restricted cubic spline model including non-adiposity-controlled estimates [14, 44, 45, 48, 50-52] is presented in ESM Fig. 2. 


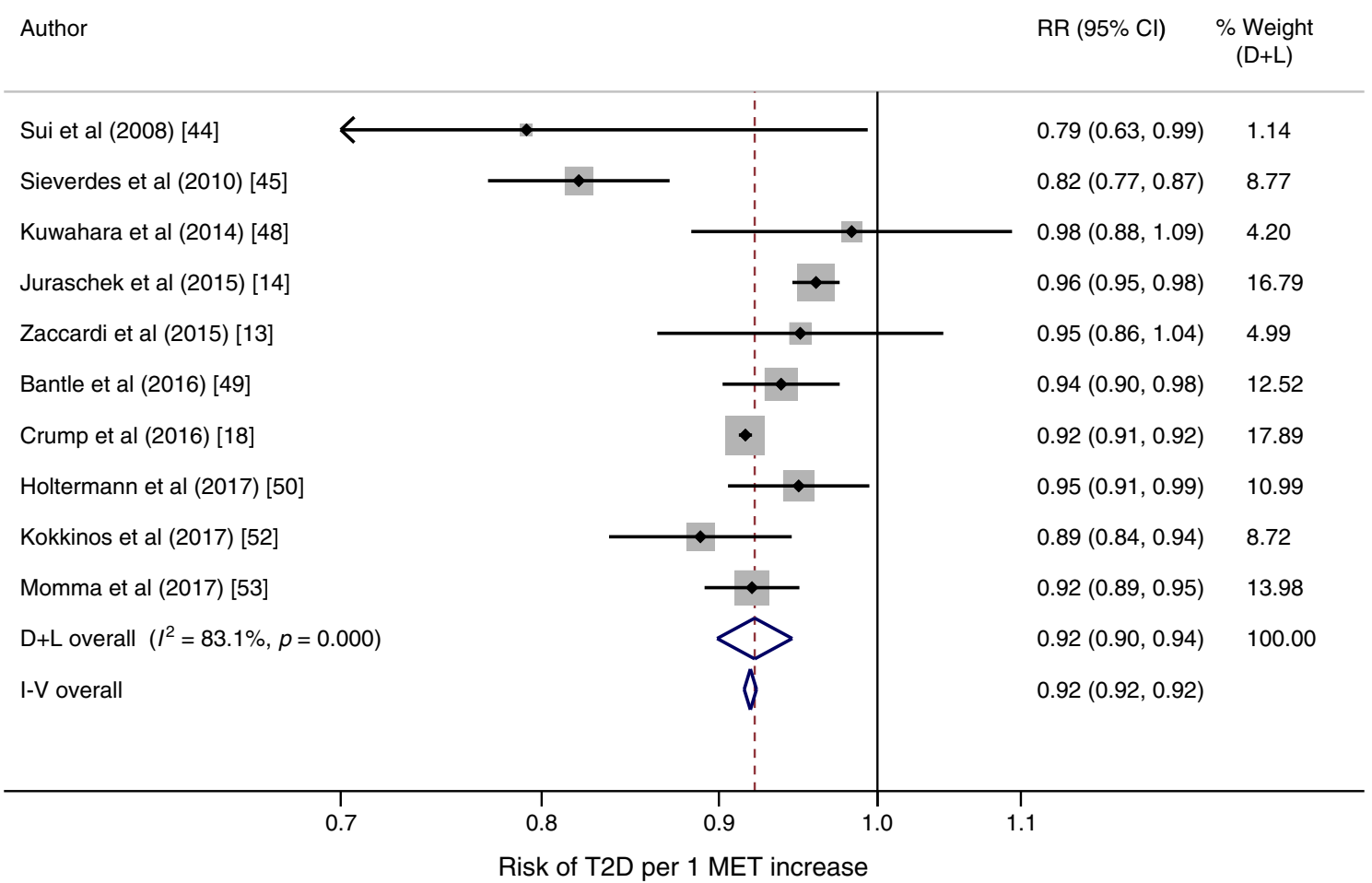

Fig. 2 Study-specific RRs per 1 MET increase in cardiorespiratory fitness in models controlling for adiposity. Study weights are from the randomeffects analysis (D+L). Pooled RRs from the random-effects analysis (D+ L) and the fixed-effects analysis (I-V) are shown based on ten cohorts providing adiposity-controlled estimates. Four of these cohorts provided estimates per 1 MET (or $\mathrm{ml} \mathrm{O}_{2} \mathrm{~kg}^{-1} \mathrm{~min}^{-1}$, converted to METs) [13, 14, $18,50]$ while the linear estimate was modelled using GLST in six studies [44, 45, 48, 49, 52, 53]. D+L, DerSimonian and Laird (random-effects model); I-V, inverse variance (fixed-effects model)

in ESM Table 12). The PIFs (adiposity-controlled) associated with a hypothetical intervention resulting in a 1 MET increase among the least fit $50 \%$ of US men and women aged $40-59$ years were $4.2 \%$ and $3.6 \%$, respectively. PIFs (adiposity-controlled) of achieving the same cardiorespiratory fitness distribution as is observed in a populationbased sample of same-aged Norwegians were $18.0 \%$ and $20.6 \%$ for men and women, respectively (Table 1 [70, 71]); PIFs based on the non-adiposity-controlled estimate are presented in ESM Table 9. The impact of stratification on the pooled RR (adiposity-controlled) is shown in Table 2. Apart from a marked difference in sex-stratified results (only one study included women only), none of our stratification parameters substantially altered the risk reduction.

Association between muscular strength and risk of type 2 diabetes In adiposity-controlled models including 39,233 incident cases and 1,713,468 participants, each SD higher muscular strength was associated with a $13 \%(95 \% \mathrm{CI} 6,19)$ lower risk of type 2 diabetes [15, 16, 18, 61-66, 68] (Fig. 4). Pooling the nine available estimates not controlled for adiposity yielded an RR of 0.76 (95\% CI $0.64,0.91)$ [15, 16, 43, 63-65, 68] per SD higher muscular strength (ESM Fig. 3). Heterogeneity was substantial in both models $\left(I^{2} 81 \%\right.$ and 
Table 1 PIFs and PAFs for counterfactual cardiorespiratory fitness distributions in 40-59-year-old US men and women

\begin{tabular}{|c|c|c|c|c|c|}
\hline Intervention & Sex & Observed CRF distribution [40] & RR per $1 \mathrm{MET}$ & Counterfactual CRF distribution & PIF \\
\hline $\begin{array}{l}1 \text { MET CRF increase achieved } \\
\text { in the least fit } 50 \%\end{array}$ & Men & $\begin{array}{l}\text { FRIEND database (US) } \\
\text { Mean } 10.37 \\
\text { SD } 2.76\end{array}$ & $\begin{array}{l}0.92 \\
\text { (adiposity-controlled) }\end{array}$ & $\begin{array}{l}\text { Mean } 10.82 \\
\text { SD } 2.38\end{array}$ & $4.2 \%$ \\
\hline $\begin{array}{l}1 \text { MET CRF increase achieved } \\
\text { in the least fit } 50 \%\end{array}$ & Women & $\begin{array}{l}\text { FRIEND database }(\mathrm{US})^{\mathrm{a}} \\
\text { Mean } 7.45 \\
\text { SD } 2.05\end{array}$ & $\begin{array}{l}0.92 \\
\text { (adiposity-controlled) }\end{array}$ & $\begin{array}{l}\text { Mean } 7.86 \\
\text { SD } 1.68\end{array}$ & $3.6 \%$ \\
\hline $\begin{array}{l}1 \text { MET CRF increase achieved } \\
\text { irrespective of initial CRF }\end{array}$ & Men & $\begin{array}{l}\text { FRIEND database (US) } \\
\text { Mean } 10.37 \\
\text { SD } 2.76\end{array}$ & $\begin{array}{l}0.92 \\
\text { (adiposity-controlled) }\end{array}$ & $\begin{array}{l}\text { Mean } 11.37 \\
\text { SD } 2.76\end{array}$ & $7.9 \%$ \\
\hline $\begin{array}{l}1 \text { MET CRF increase achieved } \\
\text { irrespective of initial CRF }\end{array}$ & Women & $\begin{array}{l}\text { FRIEND database }(\mathrm{US})^{\mathrm{a}} \\
\text { Mean } 7.45 \\
\text { SD } 2.05\end{array}$ & $\begin{array}{l}0.92 \\
\text { (adiposity-controlled) }\end{array}$ & $\begin{array}{l}\text { Mean } 8.45 \\
\text { SD } 2.05\end{array}$ & $7.8 \%$ \\
\hline $\begin{array}{l}\text { Achieve same CRF distribution } \\
\text { as age-matched Norwegian } \\
\text { population-based sample }\end{array}$ & Men & $\begin{array}{l}\text { FRIEND database }(\mathrm{US})^{\mathrm{a}} \\
\text { Mean } 10.37 \\
\text { SD } 2.76\end{array}$ & $\begin{array}{l}0.92 \\
\text { (adiposity-controlled) }\end{array}$ & $\begin{array}{l}\text { Norwegian HUNT study [41] } \\
\text { (men aged } 40-59 \text { years) } \\
\text { Mean } 12.69 \\
\text { SD } 2.31\end{array}$ & $18.0 \%$ \\
\hline $\begin{array}{l}\text { Achieve same CRF distribution } \\
\text { as age-matched Norwegian } \\
\text { population-based sample }\end{array}$ & Women & $\begin{array}{l}\text { FRIEND database }(\mathrm{US})^{\mathrm{a}} \\
\text { Mean } 7.45 \\
\text { SD } 2.05\end{array}$ & $\begin{array}{l}0.92 \\
\text { (adiposity-controlled) }\end{array}$ & $\begin{array}{l}\text { Norwegian HUNT study [41] } \\
\text { (women aged 40-59 years) } \\
\text { Mean } 10.24 \\
\text { SD } 1.92\end{array}$ & $20.6 \%$ \\
\hline $\begin{array}{l}\text { Achieve same CRF distribution } \\
\text { as most active tertile of } \\
\text { age-matched individuals from } \\
\text { a Norwegian population-based } \\
\text { sample }^{\mathrm{c}}\end{array}$ & Men & $\begin{array}{l}\text { FRIEND database }(\mathrm{US})^{\mathrm{a}} \\
\text { Mean } 10.37 \\
\text { SD } 2.76\end{array}$ & $\begin{array}{l}0.92 \\
\text { (adiposity-controlled) }\end{array}$ & $\begin{array}{l}\text { Norwegian HUNT study [41] } \\
\text { (men aged } 40-59 \text { years) } \\
\text { Mean } 14.09 \\
\text { SD } 2.31\end{array}$ & $26.8 \%$ \\
\hline $\begin{array}{l}\text { Achieve same CRF distribution } \\
\text { as most active tertile of } \\
\text { age-matched individuals from } \\
\text { a Norwegian population-based } \\
\text { sample }^{\mathrm{c}}\end{array}$ & Women & $\begin{array}{l}\text { FRIEND database }(\mathrm{US})^{\mathrm{a}} \\
\text { Mean } 7.45 \\
\text { SD } 2.05\end{array}$ & $\begin{array}{l}0.92 \\
\text { (adiposity-controlled) }\end{array}$ & $\begin{array}{l}\text { Norwegian HUNT study [41] } \\
\text { (women aged } 40-59 \text { years) } \\
\text { Mean } 11.19 \\
\text { SD } 2.08\end{array}$ & $26.2 \%$ \\
\hline $\begin{array}{l}\text { Elimination of 'unfit' category } \\
\text { (bottom } 25 \% \text { of CRF) }\end{array}$ & Men & $\begin{array}{l}\text { FRIEND database (US) } \\
\text { Mean } 10.45 \\
\text { SD } 2.77\end{array}$ & $\begin{array}{l}0.92 \\
\text { (adiposity-controlled) }\end{array}$ & - & $\begin{array}{l}\mathrm{PAF}^{\mathrm{d}} \\
8.1 \%\end{array}$ \\
\hline $\begin{array}{l}\text { Elimination of 'unfit' category } \\
\text { (bottom } 25 \% \text { of CRF) }\end{array}$ & Women & $\begin{array}{l}\text { FRIEND database }(\mathrm{US})^{\mathrm{a}} \\
\text { Mean } 7.45 \\
\text { SD } 2.05\end{array}$ & $\begin{array}{l}0.92 \\
\text { (adiposity-controlled) }\end{array}$ & - & $\begin{array}{l}\mathrm{PAF}^{\mathrm{d}} \\
5.9 \%\end{array}$ \\
\hline
\end{tabular}

${ }^{a}$ Age groups combined using the Cochrane Handbook for Systematic Reviews of Interventions, Table 7.7.a: Formulae for combining groups [70]

$\mathrm{b}$ 'Feasible minimum risk'

c 'Plausible minimum risk'

${ }^{\mathrm{d}}$ PAFs [71] for low cardiorespiratory fitness were calculated by defining the bottom $25 \%$ of the population CRF distribution as unfit ( $<8.4$ METs would be classified as unfit for men whereas women with a CRF $<6.0$ METs would be classified as unfit) based on the US FRIEND database at 40-59 years of age. We then estimated the proportion of total diabetes cases that could theoretically be prevented by changing the cardiorespiratory fitness level of all unfit adults to the fitness level matching the distribution of the population of 'fit' individuals ( $\geq 25$ th percentile). RRs were based on a contrast between the fitness level of the sex-specific 12.5th percentile (the midpoint of the 1st to 25th percentile interval) and the 62.5th percentile (the midpoint of the 25th to 99th percentile) estimated from the restricted cubic spline model. This analysis is comparable to conventional PAF calculations based on eliminating the exposure and 'shifting' exposed individuals into matching the distribution of the 'non-exposed' reference category (above the sex-specific MET cutpoints as specified above)

CRF, cardiorespiratory fitness; PAF, population attributable fraction

$91 \%$, respectively). The risk difference associated with a $1 \mathrm{SD}$ higher muscular strength (adiposity-controlled RR) was 142 $(95 \%$ CI 43,211$)$ new diabetes cases per 100,000 people per year in the US population aged 45-64 years (additional information in ESM Table 12). Studies applying normalisation of muscular strength to body weight yielded, on average, larger effect sizes $(0.83$ [ $95 \%$ CI $0.79,0.86])$ than those relying on absolute strength (0.95 [95\% CI 0.87, 1.04]).
Supplementary analyses Pooled adiposity-controlled estimates were robust to removal of single estimates with RRs ranging from 0.91 to 0.93 for cardiorespiratory fitness and from 0.86 to 0.88 for muscular strength (presented in ESM Tables 13-16). Egger's test did not indicate a risk of small-study bias in adiposity-controlled estimates ( $p=0.75$ and 0.53 ) or nonadiposity-controlled estimates for muscular fitness $(p=0.83)$. Some evidence was found in the non-adiposity-controlled 
Table 2 RR of type 2 diabetes stratified by cohort and population characteristics

\begin{tabular}{|c|c|c|c|c|c|c|}
\hline Variable & Estimates included & RR per $1 \mathrm{MET}$ & RR per SD & $95 \% \mathrm{CI}$ & $\mathrm{I}^{2}(\%)$ & $\begin{array}{l}\text { Incident type } \\
2 \text { diabetes cases }\end{array}$ \\
\hline \multicolumn{7}{|l|}{ Cardiorespiratory fitness } \\
\hline \multicolumn{7}{|l|}{ Exposure assessment } \\
\hline Sub-maximal & 3 & 0.93 & & $0.91,0.96$ & 8 & 2212 \\
\hline Maximal & 7 & 0.91 & & $0.88,0.94$ & 88 & 38,074 \\
\hline \multicolumn{7}{|l|}{ Work performed on } \\
\hline Treadmill & 5 & 0.90 & & $0.85,0.95$ & 87 & 3913 \\
\hline Bicycle ergometer & 5 & 0.92 & & $0.91,0.93$ & 10 & 36,373 \\
\hline \multicolumn{7}{|l|}{ Outcome assessment } \\
\hline Clinical assessment & 5 & 0.93 & & $0.91,0.95$ & 0 & 2383 \\
\hline Registry & 4 & 0.93 & & $0.90,0.96$ & 91 & 37,314 \\
\hline Self-report & 1 & 0.95 & & $0.77,0.87$ & - & 589 \\
\hline \multicolumn{7}{|l|}{ Region } \\
\hline North America & 5 & 0.90 & & $0.85,0.95$ & 87 & 3913 \\
\hline Scandinavia & 3 & 0.92 & & $0.90,0.94$ & 26 & 34,679 \\
\hline Japan & 2 & 0.93 & & $0.89,0.98$ & 27 & 1694 \\
\hline \multicolumn{7}{|l|}{ Sex } \\
\hline Men only & 7 & 0.91 & & $0.89,0.94$ & 67 & 38,037 \\
\hline Women only & 1 & 0.79 & & $0.63,0.99$ & - & 143 \\
\hline \multicolumn{7}{|l|}{ NOS } \\
\hline $7-8$ stars awarded & 4 & 0.92 & & $0.91,0.92$ & 3 & 35,379 \\
\hline$\leq 6$ stars awarded & 6 & 0.93 & & $0.89,0.96$ & 83 & 4907 \\
\hline \multicolumn{7}{|l|}{ Muscular strength } \\
\hline \multicolumn{7}{|c|}{ Normalisation of muscular strength } \\
\hline No normalisation & 5 & & 0.95 & $0.87,1.04$ & 65 & 3598 \\
\hline Per kg body weight & 7 & & 0.83 & $0.79,0.86$ & 68 & 35,635 \\
\hline \multicolumn{7}{|l|}{ Assessment type } \\
\hline Maximal handgrip strength & 10 & & 0.86 & $0.79,0.94$ & 79 & 4996 \\
\hline Other methods & 2 & & 0.93 & $0.72,1.21$ & 92 & 34,237 \\
\hline \multicolumn{7}{|l|}{ Outcome assessment } \\
\hline Clinical assessment & 9 & & 0.88 & $0.79,0.98$ & 83 & 2070 \\
\hline Registry & 2 & & 0.87 & $0.78,0.97$ & 79 & 36,947 \\
\hline Self-report & 1 & & 0.78 & $0.65,0.95$ & - & 216 \\
\hline \multicolumn{7}{|l|}{ Region } \\
\hline United States & 5 & & 0.98 & $0.88,1.08$ & 65 & 724 \\
\hline Other & 7 & & 0.82 & $0.77,0.87$ & 47 & 38,509 \\
\hline \multicolumn{7}{|l|}{ Sex } \\
\hline Men only & 4 & & 0.81 & $0.77,0.88$ & 0 & 34,986 \\
\hline Women only & 3 & & 0.88 & $0.72,1.09$ & 83 & 468 \\
\hline \multicolumn{7}{|l|}{ Age group } \\
\hline$<60$ years & 8 & & 0.87 & $0.80,0.95$ & 85 & 38,431 \\
\hline$\geq 60$ years & 4 & & 0.88 & $0.73,1.06$ & 72 & 802 \\
\hline \multicolumn{7}{|l|}{ NOS } \\
\hline 7-8 stars awarded & 5 & & 0.84 & $0.76,0.94$ & 88 & 35,099 \\
\hline$\leq 6$ stars awarded & 7 & & 0.90 & $0.80,1.01$ & 70 & 4134 \\
\hline
\end{tabular}

Estimates are from random-effects models controlling for adiposity

cardiorespiratory fitness estimates $(p=0.002)$. The latter appeared to be explained by the influence of one study which had by far the smallest SE and also reported the largest effect size [14]. Funnel plots are presented in ESM Figs. 4-7. 


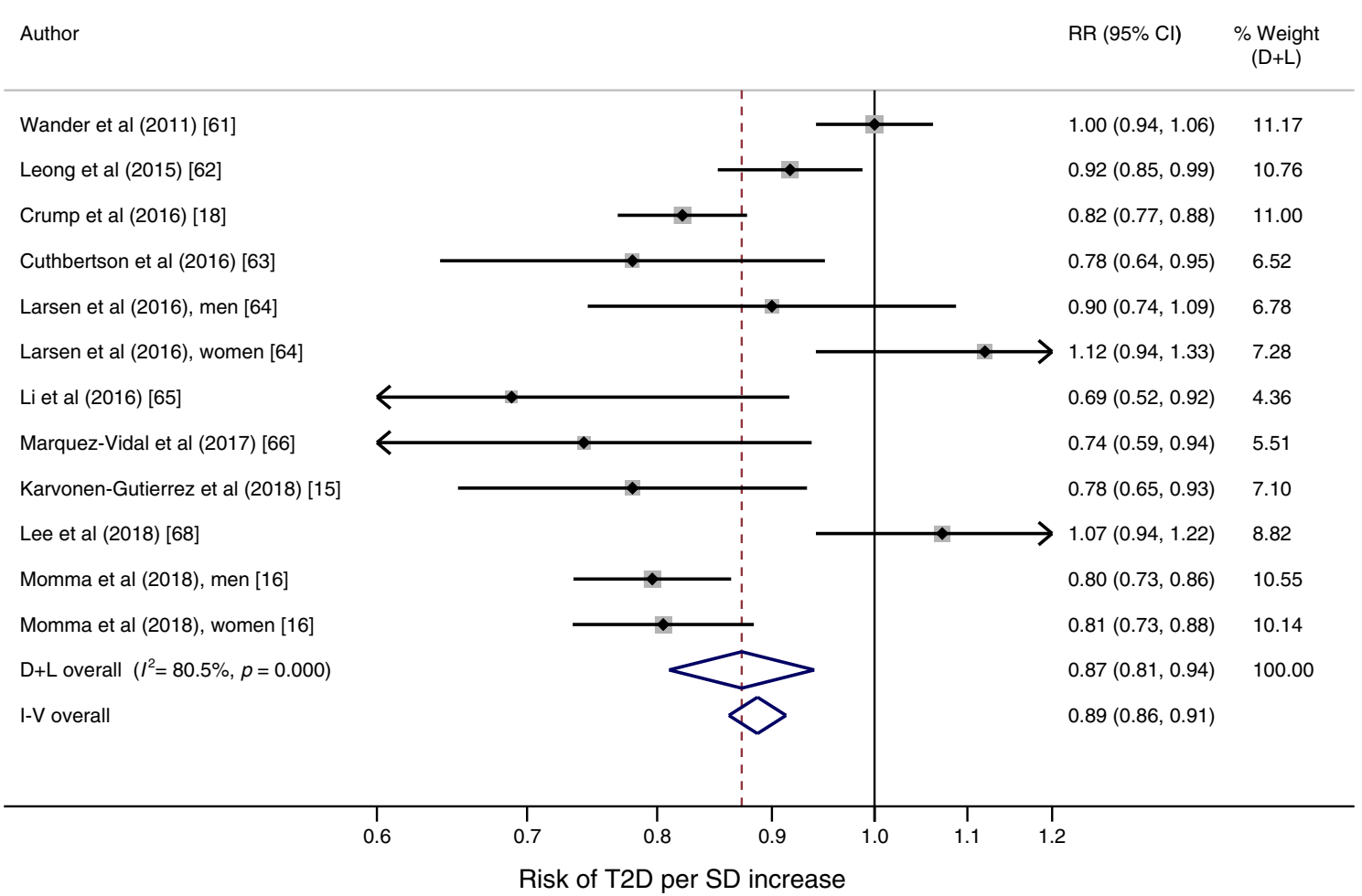

Fig. 4 Study-specific RRs per SD increase in muscular strength in models controlling for adiposity. Study weights are from the randomeffects analysis $(\mathrm{D}+\mathrm{L})$. Pooled RRs from the random-effects analysis $(\mathrm{D}+\mathrm{L})$ and the fixed-effects analysis $(\mathrm{I}-\mathrm{V})$ are shown based on ten cohorts providing adiposity-controlled estimates. Nine of these cohorts provided

\section{Discussion}

In this systematic review and dose-response meta-analysis of prospective cohort studies we found that cardiorespiratory fitness and muscular strength were inversely associated with the risk of type 2 diabetes. Our results suggest that a 1 MET increase in cardiorespiratory fitness is associated with an $8 \%$ lower risk of type 2 diabetes. A 1 SD increase in muscular strength was associated with a $13 \%$ lower risk. The magnitude of associations was about twice as large in meta-analysis of study estimates not controlling for adiposity.

The $8 \%$ diabetes risk reduction associated with a 1 MET increase is similar to the $10 \%$ reduction reported in another recently published meta-analysis on cardiorespiratory fitness [17]. We add robustness to the pooled estimate by including 11 times the number of cases and obtaining additional information or reanalysed data from original study authors. Importantly, we extend the literature by using our updated meta-analysis to estimate hypothetical benefits of population-wide improvements in cardiorespiratory fitness. These calculations inform sound judgement of estimated benefits associated with public health initiatives and are thus essential for decision making. To the best of our knowledge, this is the first quantitative synthesis of the association between muscular strength and risk of type 2 diabetes. Muscle-strengthening activities are included in the WHO per unit estimates (harmonised to per SD) $[15,16,18,61,62,63,64,66$, 68] while the linear estimate was modelled using GLST in one study [65]. D+L, DerSimonian and Laird (random-effects model); I-V, inverse variance (fixed-effects model)

physical activity guidelines for adults as an adjunct to aerobic activities [72] and higher handgrip strength is associated with lower mortality $[73,74]$. We extend the evidence base supporting higher muscle fitness as an important health marker in middleaged individuals by showing a lower risk of type 2 diabetes. We note that the RRs for muscular strength varied substantially in magnitude across original studies, ranging from a protective to a detrimental association, while RRs for cardiorespiratory fitness were more consistent. The summary RR for muscular strength should therefore be interpreted with some caution.

Our hypothetical 1 MET increase in the fitness level of the least fit $50 \%$ of the population suggested that roughly $4 \%$ of type 2 diabetes cases in the population of 40-59-year-olds in the United States could be prevented if this intervention was successfully implemented. Additionally, by modelling the PIF of a population-wide right shift of the cardiorespiratory fitness distribution of US 40-59-year-olds we show that about $21 \%$ of new annual type 2 diabetes cases could be prevented if these achieved the same cardiorespiratory fitness distribution as is observed in a same-aged contemporary Western population. Such estimates demonstrate the substantial preventive potential from major structural interventions aiming at increasing cardiorespiratory fitness at the population level. Finally, with an annual (US) incidence of type 2 diabetes in 45-65-year-olds of 1090 cases per 100,000 person-years [37], the risk differences observed with a 1 
MET and 1 SD higher fitness level suggest a strong clinical relevance of promoting and monitoring cardiorespiratory fitness and muscular strength as a part of routine primary care. Low population fitness levels are a reflection of insufficient physical activity, with the least fit being most likely to benefit with a change in structured or unstructured activity [10]. PIFs from an intervention in the lowest $50 \%$ of the cardiorespiratory fitness distribution thereby provide an estimate of benefits from a feasible intervention target. Importantly, the estimated reductions in type 2 diabetes incidence do not account for any concomitant benefits attributed to the nature of the individual-level intervention that caused fitness to increase. Such interventions include increased levels of physical activity, physical activity-associated weight-loss and/or diet-associated weight-loss.

Cardiorespiratory fitness gains of 1 MET may be achieved by taking up structured exercise for just 4 to 5 months irrespective of age, sex, weight-status and previous commitment to physical activity $[8,12]$. Importantly, a 1 MET increase in cardiorespiratory fitness may be achieved in previously inactive individuals by replacing passive with active commuting/ transportation such as walking [75] or bicycling $[76,77]$ for just a few months. A few months of resistance training may produce one-repetition maximum strength gains of $24 \%$ in the upper body [9] and substantial strength gains may be achieved across a wide range of ages and glycaemic regulatory capabilities $[5$, $78,79]$. Despite a strong correlation between handgrip and overall muscular strength [80], it is questionable whether resistance training also translates into changes in maximal handgrip strength [81]. Handgrip strength may thus have more prognostic than interventional utility [74]. As an SD difference in muscular strength corresponded to about one-third of the mean, the absolute changes required to achieve the 13\% diabetes risk reduction are also larger than for cardiorespiratory fitness.

Our restricted cubic spline model identified no threshold or levelling off of the cardiorespiratory fitness association but suggested that the type 2 diabetes risk reduction is linear throughout very low to fairly high cardiorespiratory fitness levels. This is not in agreement with observations for allcause and cardiovascular mortality where relative benefits from cardiovascular fitness gains are much higher at the lower end of the fitness spectrum [27]. We are unable to explain this difference but speculate that it may relate to differences between cardiovascular fitness reflecting overall cardiovascular integrity for cardiovascular disease protection [12] while possibly being more a marker of physical activity in relation to diabetes prevention. On that note, a Mendelian randomisation study found no association between genetic markers of higher handgrip strength and fasting glucose or type 2 diabetes risk [82]. This could suggest that it is engagement in habitual physical activity of sufficient intensity, frequency and duration to increase strength which is biologically relevant and not higher strength per se. Examination of fitness markers and risk of type 2 diabetes stratified by or in combination with physical activity may be informative in future studies. Another interesting avenue of future research would be to investigate potential synergistic effects of combined cardiorespiratory and muscular fitness in relation to diabetes risk $[18,83,84]$.

The results from our meta-analyses should be interpreted in the light of at least the following limitations: (1) A number of assumptions and calculations were required to harmonise as much data as possible and the applied assumptions may differ in their accuracy across studies. (2) Muscular strength was predominantly assessed using handgrip strength. It is therefore unknown whether other muscle groups or if other components of muscular fitness (power and endurance) share identical protective associations with type 2 diabetes. However, a cohort of more than one million men found similar associations between handgrip and knee extension strength with all-cause mortality [85]. (3) Despite highly significant between-study heterogeneity most of our stratification parameters made only minor changes to the pooled point-estimates or between-study heterogeneity. Strength cohorts were more heterogeneous with respect to age groups and exposure normalisation than was the case for cardiorespiratory fitness, which is reflected in the forest plots. (4) Cardiorespiratory fitness was routinely presented normalised to body weight $(\mathrm{kg})$. This was not the case for muscular strength. Both of these expressions are likely to be suboptimal as controlling for body weight using $\mathrm{kg} / \mathrm{kg}$ body weight may induce positive confounding [86] but failure to normalise would result in heavier individuals having, on average, higher (absolute) fitness levels. This could induce negative confounding or even the appearance of higher diabetes risk with increasing fitness. Controlling for BMI is unlikely to ameliorate heterogeneity caused by different normalisation approaches and may in itself represent an overly conservative model because physical activity engagement leading to higher fitness may also help control body weight. On the other hand, there is a consistent gradient of declining BMI with increasing fitness levels which is much larger than what is explained by engagement in physical activity alone [87]. While still incompletely understood, the optimal normalisation procedure to minimise adiposity-induced confounding appears to be normalisation to kilograms of lean body mass [88]. (5) Only one study [53] examined the potential risk of reverse causality bias by excluding from analysis all those developing type 2 diabetes within a few years of follow-up. Future studies should consider this approach. The majority of studies included in meta-analysis followed people for a sufficient time-period to expect that the influence of, for example, undiagnosed or pre-clinical cases should be minimised. (6) As this was a meta-analysis of observational studies we are unable to eliminate the possibility of error from unmeasured or imperfectly assessed confounders and other types of bias. Confounder control varied substantially across studies, but no study succeeded in accounting for 
all of our pre-determined major putative confounding variables. In addition to the assumption of causal and unbiased effect estimates, our PIF analyses further rely on strong distributional assumptions and should be interpreted cautiously.

In conclusion, our systematic review and meta-analyses provide evidence that higher cardiorespiratory fitness and muscular strength are associated with lower risk of type 2 diabetes. The cardiorespiratory fitness association was linear throughout low to high fitness levels. Physical activities that enhance cardiorespiratory fitness and/or muscular strength should be promoted to decrease risk of type 2 diabetes in individuals and populations.

Acknowledgements The authors cordially acknowledge A. Bantle (University of Minnesota), C. Crump (Icahn School of Medicine at Mount Sinai), M. Hamer (Loughborough University), K. Kuwahara (Teikyo University), P. Kokkinos (Veterans Affairs Medical Center), J. Sieverdes (College of Charleston), X. Siu (University of South Carolina), M. Yamamoto (Yamaha Corporation), Y. Wang (Iowa State University/ Radboud University Medical Center) and H. Momma (Tohoku University) for providing additional data and information pertinent to their original reports. We thank R. Copper (University College London) for sharing a data-request template developed for an unrelated study.

Data availability All data necessary to replicate analyses are presented in the manuscript.

Funding This research received no specific grant from any funding agency in the public, commercial or not-for-profit sectors. JT was funded by The TRYG Foundation (grant no. 11683) and the Research Council of Norway (grant no. 249932/F20) while contributing to this work. AG was funded by the European Research Council (grant no. 716657) and The TRYG Foundation (grant no. 115606) while contributing to this work. The study sponsor was not involved in the design of the study; the collection, analysis and interpretation of data; writing the report; or the decision to submit the report for publication. All authors had full access to all data in the study and take responsibility for the integrity of the data and the accuracy of the data analysis.

Duality of interest The authors declare that there is no duality of interest associated with this manuscript.

Contribution statement JT performed the literature search, extracted the data, performed the statistical analysis, interpreted the data, wrote the first draft and revised the manuscript. APS formulated the research question, performed the literature search, extracted the data, interpreted the data, wrote the first draft and revised the manuscript. KB performed the statistical analysis, interpreted the data and revised the manuscript. $\mathrm{AG}$ formulated the research question, interpreted the data and revised the manuscript. All authors approved the final version to be published. JT is the study guarantor, had full access to all data in the study, takes responsibility for the integrity of the data, and accuracy of the data analysis, and had the final responsibility to submit for publication.

Open Access This article is distributed under the terms of the Creative Commons Attribution 4.0 International License (http:// creativecommons.org/licenses/by/4.0/), which permits unrestricted use, distribution, and reproduction in any medium, provided you give appropriate credit to the original author(s) and the source, provide a link to the Creative Commons license, and indicate if changes were made.

\section{References}

1. NCD-RisC (2016) Worldwide trends in diabetes since 1980: a pooled analysis of 751 population-based studies with 4.4 million participants. Lancet 387:1513-1530

2. Torjesen I (2016) NHS England rolls out world's first national diabetes prevention programme. BMJ 352:11669

3. Diabetes Prevention Program Research Group (2015) Long-term effects of lifestyle intervention or metformin on diabetes development and microvascular complications over 15-year follow-up: the Diabetes Prevention Program Outcomes Study. Lancet Diabetes Endocrinol 3:866-875

4. Tuomilehto J, Lindström J, Eriksson JG et al (2001) Prevention of type 2 diabetes mellitus by changes in lifestyle among subjects with impaired glucose tolerance. N Engl J Med 344(18):1343-1350. https://doi.org/10.1056/NEJM200105033441801

5. Church TS, Blair SN, Cocreham S et al (2010) Effects of aerobic and resistance training on hemoglobin Alc levels in patients with type 2 diabetes: a randomized controlled trial. JAMA 304(20): 2253-2262. https://doi.org/10.1001/jama.2010.1710

6. Aune D, Norat T, Leitzmann M, Tonstad S, Vatten LJ (2015) Physical activity and the risk of type 2 diabetes: a systematic review and dose-response meta-analysis. Eur J Epidemiol 30(7):529-542. https://doi.org/10.1007/s10654-015-0056-z

7. Kyu HH, Bachman VF, Alexander LT et al (2016) Physical activity and risk of breast cancer, colon cancer, diabetes, ischemic heart disease, and ischemic stroke events: systematic review and doseresponse meta-analysis for the Global Burden of Disease Study 2013. BMJ 354:i3857

8. Lin X, Zhang X, Guo J et al (2015) Effects of exercise training on cardiorespiratory fitness and biomarkers of cardiometabolic health: a systematic review and meta-analysis of randomized controlled trials. J Am Heart Assoc 4:e02014

9. Peterson MD, Rhea MR, Sen A, Gordon PM (2010) Resistance exercise for muscular strength in older adults: a meta-analysis. Ageing Res Rev 9(3):226-237. https://doi.org/10.1016/j.arr.2010. 03.004

10. American College of Sports Medicine (2018) ACSM's guidelines for exercise testing and prescription, 10th edn. Wolters Kluwer Health, Philadelphia

11. Roberts HC, Denison HJ, Martin HJ et al (2011) A review of the measurement of grip strength in clinical and epidemiological studies: towards a standardised approach. Age Ageing 40(4):423-429. https://doi.org/10.1093/ageing/afr051

12. Ross R, Blair SN, Arena R et al (2016) Importance of assessing cardiorespiratory fitness in clinical practice: a case for fitness as a clinical vital sign: a scientific statement from the American Heart Association. Circulation 134(24):e653-e699. https://doi.org/10. 1161/CIR.0000000000000461

13. Zaccardi F, O'Donovan G, Webb DR et al (2015) Cardiorespiratory fitness and risk of type 2 diabetes mellitus: a 23 -year cohort study and a meta-analysis of prospective studies. Atherosclerosis 243(1): 131-137. https://doi.org/10.1016/j.atherosclerosis.2015.09.016

14. Juraschek SP, Blaha MJ, Blumenthal RS et al (2015) Cardiorespiratory fitness and incident diabetes: the FIT (Henry Ford ExercIse Testing) project. Diabetes Care 38(6):1075-1081. https://doi.org/10.2337/dc14-2714

15. Karvonen-Gutierrez CA, Peng Q, Peterson M, Duchowny K, Nan B, Harlow S (2018) Low grip strength predicts incident diabetes among mid-life women: the Michigan Study of Women's Health Across the Nation. Age Ageing 47(5):685-691. https://doi.org/10. 1093/ageing/afy067

16. Momma H, Sawada SS, Kato K et al (2018) Physical fitness tests and type 2 diabetes among Japanese: a longitudinal study from the 
Niigata Wellness Study. J Epidemiol. https://oi.org/10.2188/jea. JE20170280

17. Qiu S, Cai X, Yang B et al (2019) Association between cardiorespiratory fitness and risk of type 2 diabetes: a meta-analysis. Obesity (Silver Spring) 27(2):315-324. https://doi.org/10.1002/ oby. 22368

18. Crump C, Sundquist J, Winkleby MA, Sieh W, Sundquist K (2016) Physical fitness among Swedish military conscripts and long-term risk for type 2 diabetes mellitus: a cohort study. Ann Intern Med 164(9):577-584. https://doi.org/10.7326/M15-2002

19. Wells GA, Shea B, O'Connell D et al. (2009) The NewcastleOttawa Scale (NOS) for assessing the quality in nonrandomized studies in meta-analyses. Available from http://www.ohri.ca/ programs/clinical_epidemiology/oxford.asp. Accessed 1 February 2018

20. Pan A, Wang Y, Talaei M, Hu FB, Wu T (2015) Relation of active, passive, and quitting smoking with incident type 2 diabetes: a systematic review and meta-analysis. Lancet Diabetes Endocrinol 3(12):958-967. https://doi.org/10.1016/S2213-8587(15)00316-2

21. Mozaffarian D (2015) Diverging global trends in heart disease and type 2 diabetes: the role of carbohydrates and saturated fats. Lancet Diabetes Endocrinol 3(8):586-588. https://doi.org/10.1016/S22138587(15)00208-9

22. Li XH, Yu FF, Zhou YH, He J (2016) Association between alcohol consumption and the risk of incident type 2 diabetes: a systematic review and dose-response meta-analysis. Am J Clin Nutr 103(3): 818-829. https://doi.org/10.3945/ajcn.115.114389

23. Grontved A, Hu FB (2011) Television viewing and risk of type 2 diabetes, cardiovascular disease, and all-cause mortality: a metaanalysis. JAMA 305(23):2448-2455. https://doi.org/10.1001/ jama.2011.812

24. Chene G, Thompson SG (1996) Methods for summarizing the risk associations of quantitative variables in epidemiologic studies in a consistent form. Am J Epidemiol 144(6):610-621. https://doi.org/ 10.1093/oxfordjournals.aje.a008971

25. Sidney S, Haskell WL, Crow R et al (1992) Symptom-limited graded treadmill exercise testing in young adults in the CARDIA study. Med Sci Sports Exerc 24(2):177-183

26. Fletcher GF, Balady G, Froelicher VF, Hartley LH, Haskell WL, Pollock ML (1995) Exercise standards. A statement for healthcare professionals from the American Heart Association. Writing Group. Circulation 91(2):580-615. https://doi.org/10.1161/01.CIR.91.2.580

27. Kodama S, Saito K, Tanaka S et al (2009) Cardiorespiratory fitness as a quantitative predictor of all-cause mortality and cardiovascular events in healthy men and women: a meta-analysis. JAMA 301(19):2024-2035. https://doi.org/10.1001/jama.2009.681

28. Hamling J, Lee P, Weitkunat R, Ambuhl M (2008) Facilitating meta-analyses by deriving relative effect and precision estimates for alternative comparisons from a set of estimates presented by exposure level or disease category. Stat Med 27(7):954-970. https://doi.org/10.1002/sim.3013

29. DerSimonian R, Laird N (1986) Meta-analysis in clinical trials. Control Clin Trials 7(3):177-188. https://doi.org/10.1016/01972456(86)90046-2

30. Orsini N, Bellocco R, Greenland S (2006) Generalized least squares for trend estimation of summarized dose-response data. Stata $\mathrm{J}$ 6(1):40-57. https://doi.org/10.1177/1536867X0600600103

31. Greenland S, Longnecker MP (1992) Methods for trend estimation from summarized dose-response data, with applications to metaanalysis. Am J Epidemiol 135(11):1301-1309. https://doi.org/10. 1093/oxfordjournals.aje.a116237

32. Liu Q, Cook NR, Bergström A, Hsieh CC (2009) A two-stage hierarchical regression model for meta-analysis of epidemiologic nonlinear dose-response data. Comput Stat Data Anal 53(12): 4157-4167. https://doi.org/10.1016/j.csda.2009.05.001
33. White IR (2009) Multivariate random-effects meta-analysis. Stata J 9(1):40-56. https://doi.org/10.1177/1536867X0900900103

34. Orsini N, Li R, Wolk A, Khudyakov P, Spiegelman D (2012) Metaanalysis for linear and nonlinear dose-response relations: examples, an evaluation of approximations, and software. Am J Epidemiol 175(1):66-73. https://doi.org/10.1093/aje/kwr265

35. Davies HT, Crombie IK, Tavakoli M (1998) When can odds ratios mislead? BMJ 316(7136):989-991. https://doi.org/10.1136/bmj. 316.7136.989

36. Newcombe RG, Bender R (2014) Implementing GRADE: calculating the risk difference from the baseline risk and the relative risk. Evid Based Med 19(1):6-8. https://doi.org/10.1136/eb-2013101340

37. Centers for Disease Control and Prevention (CDC) (2017) National diabetes statistics report, 2017: estimates of diabetes and its burden in the United States. Available from https://www.cdc.gov/diabetes/ $\mathrm{pdfs} /$ data/statistics/national-diabetes-statistics-report.pdf. Accessed 1 October 2017

38. Barendregt JJ, Veerman JL (2010) Categorical versus continuous risk factors and the calculation of potential impact fractions. $\mathrm{J}$ Epidemiol Community Health 64(3):209-212. https://doi.org/10. 1136/jech.2009.090274

39. Rehm J, Taylor B, Patra J, Gmel G (2006) Avoidable burden of disease: conceptual and methodological issues in substance abuse epidemiology. Int J Methods Psychiatr Res 15(4):181-191

40. Kaminsky LA, Arena R, Myers J (2015) Reference standards for cardiorespiratory fitness measured with cardiopulmonary exercise testing: data from the Fitness Registry and the Importance of Exercise National Database. Mayo Clin Proc 90(11):1515-1523. https://doi.org/10.1016/j.mayocp.2015.07.026

41. Aspenes ST, Nilsen TI, Skaug EA et al (2011) Peak oxygen uptake and cardiovascular risk factors in 4631 healthy women and men. Med Sci Sports Exerc 43(8):1465-1473. https://doi.org/10.1249/ MSS.0b013e31820ca81c

42. Lynch J, Helmrich SP, Lakka TA et al (1996) Moderately intense physical activities and high levels of cardiorespiratory fitness reduce the risk of non-insulin-dependent diabetes mellitus in middle-aged men. Arch Intern Med 156(12):1307-1314. https:/ doi.org/10.1001/archinte.1996.00440110073010

43. Katzmarzyk PT, Craig CL, Gauvin L (2007) Adiposity, physical fitness and incident diabetes: the physical activity longitudinal study. Diabetologia 50(3):538-544. https://doi.org/10.1007/ s00125-006-0554-3

44. Sui X, Hooker SP, Lee IM et al (2008) A prospective study of cardiorespiratory fitness and risk of type 2 diabetes in women. Diabetes Care 31(3):550-555. https://doi.org/10.2337/dc07-1870

45. Sieverdes JC, Sui X, Lee DC et al (2010) Physical activity, cardiorespiratory fitness and the incidence of type 2 diabetes in a prospective study of men. Br J Sports Med 44(4):238-244. https://doi.org/ 10.1136/bjsm.2009.062117

46. Carnethon MR, Sternfeld B, Schreiner PJ et al (2009) Association of 20-year changes in cardiorespiratory fitness with incident type 2 diabetes: the coronary artery risk development in young adults (CARDIA) fitness study. Diabetes Care 32(7):1284-1288. https:// doi.org/10.2337/dc08-1971

47. Skretteberg PT, Grytten AN, Gjertsen K et al (2013) Triglyceridesdiabetes association in healthy middle-aged men: modified by physical fitness? A long term follow-up of 1962 Norwegian men in the Oslo Ischemia Study. Diabetes Res Clin Pract 101(2):201209. https://doi.org/10.1016/j.diabres.2013.06.001

48. Kuwahara K, Uehara A, Kurotani K et al (2014) Association of cardiorespiratory fitness and overweight with risk of type 2 diabetes in Japanese men. PLoS One 9(6):e98508. https://doi.org/10.1371/ journal.pone.0098508

49. Bantle AE, Chow LS, Steffen LM et al (2016) Association of Mediterranean diet and cardiorespiratory fitness with the 
development of pre-diabetes and diabetes: the Coronary Artery Risk Development in Young Adults (CARDIA) study. BMJ Open Diabetes Res Care 4(1):e000229. https://doi.org/10.1136/bmjdrc2016-000229

50. Holtermann A, Gyntelberg F, Bauman A, Thorsten Jensen M (2017) Cardiorespiratory fitness, fatness and incident diabetes. Diabetes Res Clin Pract 134:113-120. https://doi.org/10.1016/j. diabres.2017.10.001

51. Kawakami R, Sawada SS, Lee IM et al (2018) Long-term impact of cardiorespiratory fitness on type 2 diabetes incidence: a cohort study of Japanese men. J Epidemiol 5:266-273

52. Kokkinos P, Faselis C, Narayan P et al (2017) Cardiorespiratory fitness and incidence of type 2 diabetes in United States veterans on statin therapy. Am J Med 130(10):1192-1198. https://doi.org/10. 1016/j.amjmed.2017.04.042

53. Momma H, Sawada SS, Lee IM et al (2017) Consistently high level of cardiorespiratory fitness and incidence of type 2 diabetes. Med Sci Sports Exerc 49(10):2048-2055. https://doi.org/10.1249/MSS. 0000000000001319

54. Ohlson LO, Larsson B, Bjorntorp P et al (1988) Risk factors for type 2 (non-insulin-dependent) diabetes mellitus. Thirteen and onehalf years of follow-up of the participants in a study of Swedish men born in 1913. Diabetologia 31:798-805

55. Williams PT (2008) Relationship of running intensity to hypertension, hypercholesterolemia, and diabetes. Med Sci Sports Exerc 40(10): 1740-1748. https://doi.org/10.1249/MSS.0b013e31817b8ed1

56. Kinney GL, Baker E, Klein OL et al (2014) Incident diabetes mellitus in heavy smokers. Diabetes 1:A365 (Abstract)

57. Someya Y, Kawai S, Kohmura Y, Aoki K, Daida H (2014) Cardiorespiratory fitness and the incidence of type 2 diabetes: a cohort study of Japanese male athletes. BMC Public Health 14(1):493. https://doi.org/10.1186/1471-2458-14-493

58. Jae SY, Franklin BA, Choo J, Yoon ES, Choi YH, Park WH (2016) Fitness, body habitus, and the risk of incident type 2 diabetes mellitus in Korean men. Am J Cardiol 117(4):585-589. https:// doi.org/10.1016/j.amjcard.2015.11.046

59. Sydo N, Sydo T, Carta KG et al (2016) Cardiovascular fitness reduces the risk of weight-associated comorbidities and all-cause mortality in past smokers. J Am Coll Cardiol 1:1858

60. Wu CJ, Kao TW, Yang HF et al (2018) Predictability of cardiorespiratory fitness on the risk of developing metabolic syndrome and diabetes mellitus in Taiwan adults: preliminary analysis of a cohort study. Obes Res Clin Pract 12(6):541-546. https://doi.org/10.1016/ j.orcp.2018.07.006

61. Wander PL, Boyko EJ, Leonetti DL, McNeely MJ, Kahn SE, Fujimoto WY (2011) Greater hand-grip strength predicts a lower risk of developing type 2 diabetes over 10 years in leaner Japanese Americans. Diabetes Res Clin Pract 92(2):261-264. https://doi.org/ 10.1016/j.diabres.2011.01.007

62. Leong DP, Teo KK, Rangarajan S et al (2015) Prognostic value of grip strength: findings from the Prospective Urban Rural Epidemiology (PURE) study. Lancet 386(9990):266-273. https:// doi.org/10.1016/S0140-6736(14)62000-6

63. Cuthbertson DJ, Bell JA, Ng SY, Kemp GJ, Kivimaki M, Hamer M (2016) Dynapenic obesity and the risk of incident type 2 diabetes: the English Longitudinal Study of Ageing. Diabet Med 33(8): 1052-1059. https://doi.org/10.1111/dme.12991

64. Larsen BA, Wassel CL, Kritchevsky SB et al (2016) Association of muscle mass, area, and strength with incident diabetes in older adults: the Health ABC Study. J Clin Endocrinol Metab 101(4): 1847-1855. https://doi.org/10.1210/jc.2015-3643

65. Li JJ, Wittert GA, Vincent A et al (2016) Muscle grip strength predicts incident type 2 diabetes: population-based cohort study. Metabolism 65(6):883-892. https://doi.org/10.1016/j.metabol. 2016.03.011
66. Marques-Vidal P, Vollenweider P, Waeber G, Jornayvaz FR (2017) Grip strength is not associated with incident type 2 diabetes mellitus in healthy adults: the CoLaus study. Diabetes Res Clin Pract 132: 144-148. https://doi.org/10.1016/j.diabres.2017.08.004

67. McGrath RP, Vincent BM, Snih SA et al (2017) The association between handgrip strength and diabetes on activities of daily living disability in older Mexican Americans. J Aging Health 30:1305-1318

68. Lee DC, Brellenthin A, Sui X, Blair S (2018) Muscular strength and type 2 diabetes prevention. Circulation 137:MP32 (Abstract)

69. Zhang W, Yang X, Han P et al (2018) Risk factors for developing diabetes among community dwelling elderly with impaired fasting glycaemia after 3 years. J Diabetes 11:107-114

70. Higgins JPT, Green S (eds) (2011) Cochrane handbook for systematic reviews of interventions 5.1.0 [updated March 2011]. The Cochrane Collaboration. Available from http://handbook-5-1. Cochrane.org/. Accessed 1 November 2017

71. Lee IM, Shiroma EJ, Lobelo F, Puska P, Blair SN, Katzmarzyk PT (2012) Effect of physical inactivity on major non-communicable diseases worldwide: an analysis of burden of disease and life expectancy. Lancet 380(9838):219-229. https://doi.org/10.1016/ S0140-6736(12)61031-9

72. World Health Organization (2010) WHO global strategy on diet, physical activity and health. Global recommendations on physical activity for health. Available from http://www.who.int/dietphysicalactivity/ factsheet_recommendations/en/. Accessed 1 June 2018

73. Grontved A, Hu FB (2017) Walking pace and handgrip strength: simple measures of fitness and mortality risk? Eur Heart J 38(43): 3241-3243. https://doi.org/10.1093/eurheartj/ehx497

74. Celis-Morales CA, Welsh P, Lyall DM et al (2018) Associations of grip strength with cardiovascular, respiratory, and cancer outcomes and all cause mortality: prospective cohort study of half a million UK Biobank participants. BMJ 361:k1651

75. Murtagh EM, Nichols L, Mohammed MA, Holder R, Nevill AM, Murphy MH (2015) The effect of walking on risk factors for cardiovascular disease: an updated systematic review and metaanalysis of randomised control trials. Prev Med 72:34-43. https:// doi.org/10.1016/j.ypmed.2014.12.041

76. Moller NC, Ostergaard L, Gade JR, Nielsen JL, Andersen LB (2011) The effect on cardiorespiratory fitness after an 8-week period of commuter cycling - a randomized controlled study in adults. Prev Med 53(3):172-177. https://doi.org/10.1016/j.ypmed.2011.06.007

77. Quist JS, Rosenkilde M, Petersen MB, Gram AS, Sjodin A, Stallknecht B (2017) Effects of active commuting and leisuretime exercise on fat loss in women and men with overweight and obesity: a randomized controlled trial. Int J Obes 42:469-478

78. Hubal MJ, Gordish-Dressman H, Thompson PD et al (2005) Variability in muscle size and strength gain after unilateral resistance training. Med Sci Sports Exerc 37(6):964-972

79. Davy BM, Winett RA, Savla J et al (2017) Resist diabetes: a randomized clinical trial for resistance training maintenance in adults with prediabetes. PLoS One 12(2):e0172610. https://doi.org/10. 1371/journal.pone. 0172610

80. Wind AE, Takken T, Helders PJ, Engelbert RH (2010) Is grip strength a predictor for total muscle strength in healthy children, adolescents, and young adults? Eur J Pediatr 169(3):281-287. https://doi.org/10.1007/s00431-009-1010-4

81. Tieland M, Verdijk LB, de Groot LC, van Loon LJ (2015) Handgrip strength does not represent an appropriate measure to evaluate changes in muscle strength during an exercise intervention program in frail older people. Int J Sport Nutr Exerc Metab 25(1):27-36. https://doi.org/10.1123/ijsnem.2013-0123

82. Xu L, Hao YT (2017) Effect of handgrip on coronary artery disease and myocardial infarction: a Mendelian randomization study. Sci Rep 7(1):954. https://doi.org/10.1038/s41598-017-01073-z

83. Crump C, Sundquist J, Winkleby MA, Sundquist K (2017) Interactive effects of obesity and physical fitness on risk of 
ischemic heart disease. Int J Obes 41(2):255-261. https://oi.org/ 10.1038/ijo.2016.209

84. Grontved A, Ried-Larsen M, Ekelund U, Froberg K, Brage S, Andersen LB (2013) Independent and combined association of muscle strength and cardiorespiratory fitness in youth with insulin resistance and beta-cell function in young adulthood: the European Youth Heart Study. Diabetes Care 36(9):2575-2581. https://doi. org $/ 10.2337 / \mathrm{dc} 12-2252$

85. Ortega FB, Silventoinen K, Tynelius P, Rasmussen F (2012) Muscular strength in male adolescents and premature death: cohort study of one million participants. BMJ 345:e7279. https://doi.org/ 10.1136/bmj.e7279

86. Savonen K, Krachler B, Hassinen M et al (2012) The current standard measure of cardiorespiratory fitness introduces confounding by body mass: the DR's EXTRA study. Int J Obes 36(8):11351140. https://doi.org/10.1038/ijo.2011.212

87. Swift DL, Johannsen NM, Lavie CJ, Earnest CP, Church TS (2014) The role of exercise and physical activity in weight loss and maintenance. Prog Cardiovasc Dis 56(4):441-447. https://doi.org/10. 1016/j.pcad.2013.09.012

88. Krachler B, Savonen K, Komulainen P, Hassinen M, Lakka TA, Rauramaa R (2015) Cardiopulmonary fitness is a function of lean mass, not total body weight: the DR's EXTRA study. Eur J Prev Cardiol 22(9):1171-1179. https://doi.org/10.1177/2047487314557962

Publisher's note Springer Nature remains neutral with regard to jurisdictional claims in published maps and institutional affiliations. 